Sun International Journal of Engineering and Basic Sciences

\title{
Insitu Fabrication of Aluminium Titanium Diboride Composite
}

H. Hiru Purushothaman*, S. Arun Kumar, Debarshi Kattyayan, Samanvay Mishra, Shivkumar Patel

Department of Mechanical Engineering, SRM University, Chennai

*Corresponding author: E-Mail: hirupurushothaman.h@ktr.srmuniv.ac.in

\section{ABSTRACT}

In metal matrix composites, a metal is often combined with another, a non-metallic, phase to produce a novel material possessing attractive engineering attributes of its own. A subject of research in the 1980s and 1990s, this class of materials has, in the past ten years, increased significantly in variety. Aluminium matrix composites (AMCs) refer to the group of light weight, high performance, aluminium centric material systems.

This project emphasises on casting a $\mathrm{Al}-\mathrm{TiB}_{2}$ metal-matrix composites fabricated using an exothermic reaction process using $\mathrm{K}_{2} \mathrm{TiF}_{6}$ and $\mathrm{KBF}_{4}$ salts. The possibility of developing simple, cost effective and efficient processing routes for the production of metal matrix composites was used. These insitu prepared composites were characterized using scanning electron microscope. The dry sliding wear behaviour of the prepared composite was compared. Also, the study at room temperature was carried out for comparison purpose. The results indicate that the wear rate decreases with the increase in the weight percentage of $\mathrm{TiB}_{2}$, while it increases with the increase in the applied load.

KEY WORDS: Aluminum Titanium Diboride, Insitu.

\section{INTRODUCTION}

A metal matrix composite (MMC) is a composite material with at least two constituent parts, one necessarily being a metal, the other material may be a different metal or another material, such as a ceramic or organic compound. MMCs have emerged as an important category of materials for structural, wear, thermal, transportation and electrical applications because of their ability to exhibit superior strength-to-weight and strength-to-cost ratios when compared to equivalent monolithic commercial alloys. The possibility of developing simple, cost effective and efficient processing routes for the production of metal matrix composites is currently being explored by materials researchers from most developing countries. The reinforcement in AMCs, the class of light weight high performance aluminium centric material systems could be in the form of continuous or discontinuous fibres or particulates, in volume fractions ranging from a few percent to $70 \%$.

The current project work is an effort to study the mechanical behaviour of Aluminium and $\mathrm{TiB}_{2}$ composites produced using stir casting process. Both alloy and composites were prepared using the in situ fabrication technique. In situ fabrication of MMC is a process, in which dispersed reinforcing phase is formed in the matrix as a result of precipitation from the melt during its cooling and solidification. This contrasts with ex-situ composites where the reinforcing phase is synthesized separately and then inserted into the matrix during a secondary process.

\section{EXPERIMENTAL PROCEDURES}

The complete experimental procedure comprises of two casting processes-

- To form the Aluminium Matrix alloy consisting of 0.75\% Magnesium and 7.0\% Silicon.

- To reinforce the Aluminium Matrix with Insitu $\mathrm{TiB}_{2}$, produced as a reaction product of salts $\mathrm{K}_{2} \mathrm{TiF}_{6}$ and $\mathrm{KBF}_{4}$.

To cast the Aluminium based alloy 1000 gm of pure Aluminium was carefully weighted and placed inside a clay-graphite crucible kept inside the furnace core which is maintained at $850^{\circ} \mathrm{C}$. After about 40 minutes, Aluminium melts and $70 \mathrm{gm}$ Silicon and $7.5 \mathrm{gm}$ Magnesium is then added in the melt. Take note that Magnesium is perfectly submerged inside melt otherwise Magnesium at that temperature reacts with oxygen very fast and starts burning. The melt is then stirred rapidly for some time, keeping in notice that the Magnesium is perfectly submerged inside the melt. Before poring the molten alloy for casting, the oxidised top layer in the melt is removed using a graphite rod because graphite does not react with the melt and has a very high melting point. The molten alloy is carefully poured into the mould.

The $\mathrm{TiB}_{2}$ reinforcement was synthesised using two types of salt Potassium Hexaflurotitanate $\left(\mathrm{K}_{2} \mathrm{TiF}_{6}\right)$ and Potassium Tetrafluroborate $\left(\mathrm{KBF}_{4}\right)$. The exothermic reaction between the salts yield in situ formed $\mathrm{TiB}_{2}$ particulates in the alloy. The salts such as $\mathrm{K}_{2} \mathrm{TiF}_{6}$ and $\mathrm{KBF}_{4}$ were carefully measured and preheated at $150^{\circ} \mathrm{C}$ for two hours remove any moisture residue from the salts. A 1000 gms of the Aluminium alloy was then melted in a pure graphite crucible at $800^{\circ} \mathrm{C}$. The preheated mixture of powder salts $\mathrm{K}_{2} \mathrm{TiF}_{6}$ and $\mathrm{KBF}_{4}$ is then packed into small pouches of aluminium foil. The pouches are then carefully added to the alloy melt and stirred well in order to distribute the salt in the melt uniformly. The exothermic reaction between the salts yield insitu formed $\mathrm{TiB}_{2}$ particulates in the alloy. Stir the mixture rapidly for 30 seconds after each 5-minute interval for 1 hour. This is done because the reaction process of the salts and the alloy melt yields potassium fluoride as by-product which is highly injurious and oxidation 
Sun International Journal of Engineering and Basic Sciences

make the slag volume increase. After removing slag, the melt is carefully poured into the preheated moulds for Gravity casting.

\section{RESULT AND DISCUSSION}

Characterization Test: Table.1, shows the chemical composition of the aluminium alloy along with the aluminium alloy reinforced with $6 \%$ and $2 \% \mathrm{TiB}_{2}$.

The table value shows the percentage of various elements present in the alloy before and after reinforcement with titanium diboride. The amount of magnesium in the alloy shows a decrease in amount than the theoretically calculated value which is due to evaporation of magnesium during melting in the furnace. We can also observe the presence of titanium particles in the alloy after reinforcing it with titanium diboride. The loss in the amount of magnesium does not affect the hardness and wear properties of the alloy as the major contributor of hardness to the alloy is the presence of titanium diboride particles present in the aluminium matrix.

Table.1. Chemical composition of Alloy and Composite

\begin{tabular}{|l|l|l|l|l|l|l|l|l|l|}
\hline Element (wt.\%) & $\mathbf{M g}$ & $\mathbf{S i}$ & $\mathbf{F e}$ & $\mathbf{C u}$ & $\mathbf{M n}$ & $\mathbf{Z n}$ & $\mathbf{T i}$ & $\mathbf{C r}$ & Al \\
\hline $0 \% \mathrm{TiB}_{2}$ & 0.696 & 0.700 & 0.100 & 0.014 & 0.100 & 0.090 & 0.000 & 0.000 & Bal. \\
\hline $6 \% \mathrm{TiB}_{2}$ & 0.159 & 8.010 & 0.181 & 0.014 & 0.090 & 0.094 & 7.880 & 0.003 & Bal. \\
\hline $2 \% \mathrm{TiB}_{2}$ & 0.133 & 7.905 & 0.192 & 0.015 & 0.090 & 0.093 & 3.550 & 0.004 & Bal. \\
\hline
\end{tabular}

Micro hardness test:

Aluminium alloy:

Table.2. shows the hardness values of aluminium alloy.

\begin{tabular}{|l|l|l|l|}
\hline Wt.\% $\mathbf{T i B}_{2}$ & $\mathbf{H v}_{(\mathbf{0 . 2})}$ & $\mathbf{H v}_{(\mathbf{0 . 5})}$ & $\mathbf{H v}_{(\mathbf{1 . 0})}$ \\
\hline $0 \%$ & 63 & 62 & 59 \\
\hline & 66 & 61 & 58 \\
\hline & 69 & 60 & 56 \\
\hline
\end{tabular}

The hardness test is carried out on three different samples of the alloy with varying loads of $0.2,0.5$ and $1.0 \mathrm{~kg}$. Figure.1, indicates a decrease in the value of hardness with the increase in the load applied.

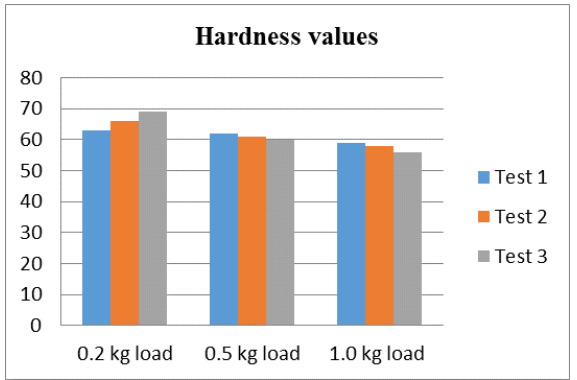

Figure.1. Hardness value test on aluminium alloy for varying loads

Aluminium Alloy Reinforced With $2 \% \mathbf{T i B}_{2}$ : Table.3, shows the hardness values of $2 \%$ composite. The hardness test is carried out on three different samples of the $2 \% \mathrm{TiB}_{2}$ with varying loads of $0.2,0.5$ and $1.0 \mathrm{~kg}$. Figure.2, indicates a decrease in the value of hardness with the increase in the load applied.

Table.3. Hardness test values on $2 \%$ composite

\begin{tabular}{|l|l|l|l|}
\hline Wt.\% $\mathbf{T i B}_{\mathbf{2}}$ & $\mathbf{H v}_{(\mathbf{0 . 2})}$ & $\mathbf{H v}_{(\mathbf{0 . 5})}$ & $\mathbf{H v}_{(\mathbf{1 . 0 )}}$ \\
\hline $2 \%$ & 83 & 79 & 72 \\
\hline & 85 & 77 & 70 \\
\hline & 81 & 75 & 71 \\
\hline
\end{tabular}

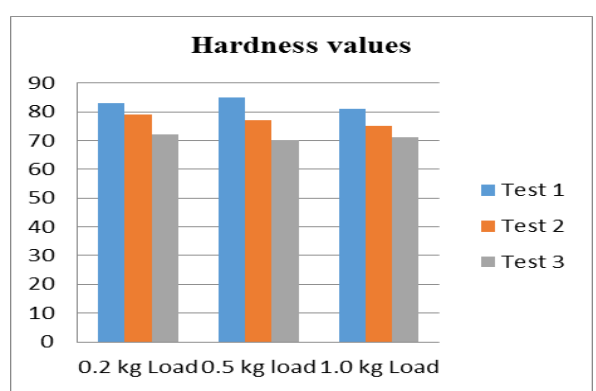

Figure.2. Hardness value test on $2 \%$ composite for varying loads

Aluminium Alloy Reinforced With 6\% TiB 2 : Table.4, shows the hardness values of $6 \%$ composite. The hardness test is carried out on three different samples of the $6 \% \mathrm{TiB} 2$ sample with varying loads of $0.2,0.5$ and $1.0 \mathrm{~kg}$. Figure.3, indicates a decrease in the value of hardness with the increase in the load applied. 
Sun International Journal of Engineering and Basic Sciences

Table.4. Hardness test values on $6 \%$ composite

\begin{tabular}{|l|l|l|l|}
\hline Wt. \% $\mathbf{T i B}_{\mathbf{2}}$ & $\mathbf{H v}_{(\mathbf{0 . 2})}$ & $\mathbf{H v}_{(\mathbf{0 . 5})}$ & $\mathbf{H v}_{(\mathbf{1 . 0})}$ \\
\hline $6 \%$ & 89 & 78 & 75 \\
\hline & 87 & 79 & 73 \\
\hline & 88 & 77 & 71 \\
\hline
\end{tabular}

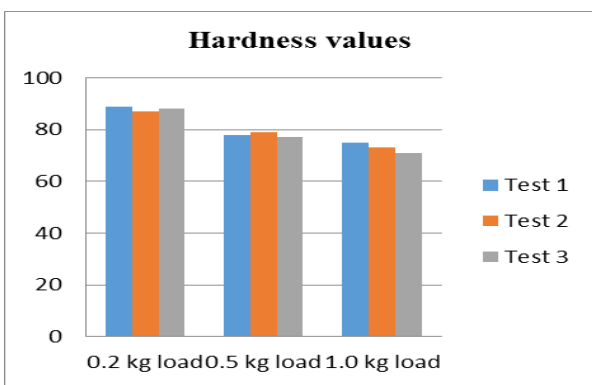

Figure.3. Hardness value test on $6 \%$ composite for varying loads

Hardness Comparision among Aluminium Alloy and 2\%, 6\% Composite: Figure.4, shows the hardness comparison among aluminium alloy and $2 \%, 6 \%$ composite. Figure.4, shows a marked improvement in the hardness value of the composite as compared to that of the aluminium alloy.

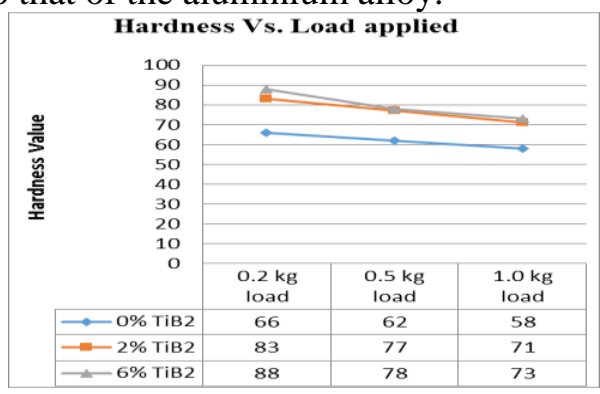

Figure.4. Hardness comparison among aluminium alloy and $2 \%, 6 \%$ composite

The hardness value also decreases for all the samples with an increase in the load applied. The $6 \% \mathrm{TiB}_{2}$ sample shows the highest hardness value among the three samples followed by the $2 \% \mathrm{TiB}_{2}$ sample and the aluminium alloy. The hardness values decreases steeply for the reinforced samples when the load applied increases from $0.2 \mathrm{~kg}$ to $0.5 \mathrm{~kg}$ and thereafter the decrease is gradual. This indicates that the composite has high hardness values for lower loads and the value decreases as the amount of load applied is increased.

Wear Load Test: The wear rate is compared between the normal alloy (unreinforced) and the reinforced composites in this section. It is found from Figure that the wear rate of both matrix alloy and composite specimens increased with increase in applied load. However, a lower wear rate was obtained for the MMC alloy when compared with matrix alloy. Also, the wear rate decreased with an increase in $\mathrm{TiB}_{2}$ content in the $\mathrm{Al} / \mathrm{TiB} \mathrm{MMC}_{2} \mathrm{MMecimens}$.

Aluminium Alloy: Table.5, shows the result of wear load test conducted on aluminium alloy.

Table.5. Wear load test values on aluminium alloy

\begin{tabular}{|l|l|l|l|l|}
\hline Load Applied & Initial Weight (gm) & Final Weight (gm) & Abrasion Loss (gm) & Loss \% \\
\hline $1 \mathrm{Kg}$ & 1.6762 & 1.4215 & 0.2547 & 15.19 \\
\hline $2 \mathrm{Kg}$ & 1.3589 & 1.0174 & 0.3415 & 25.13 \\
\hline $3 \mathrm{Kg}$ & 1.1400 & 0.6710 & 0.4690 & 41.14 \\
\hline
\end{tabular}

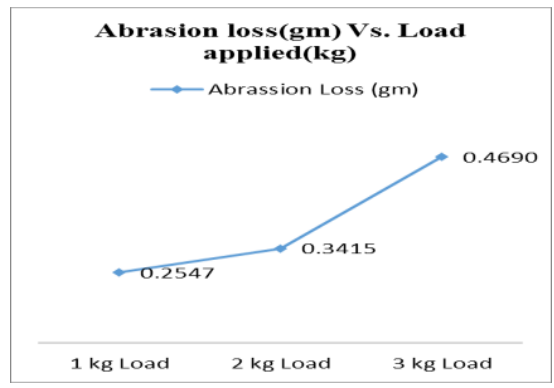

Figure.5. Wear test in aluminium alloy as a function of weight loss

Figure.5, shows that the abrasion loss increases with the load applied for the aluminium alloy. The loss is minimum at the starting when the load applied is $1 \mathrm{~kg}$ and increases thereafter with the load applied. 
Sun International Journal of Engineering and Basic Sciences

The results indicate that at lower loads, relatively low wear rates exist, indicating the regime of mild wear in which the composites demonstrate significant wear-resistance than the alloy counterpart. At higher loads, the materials show a quick increase in wear rate. At loads greater than transition load, severe wear occurs leading to seizure of the materials

Aluminium Alloy Reinforced with 2\% $\mathbf{T i B}_{2}$ : Table.6, shows the result of wear load test conducted on $2 \%$ composite.

Table.6. Wear load test values on $2 \%$ composite

\begin{tabular}{|l|l|l|l|l|}
\hline Load Applied & Initial Weight (gm) & Final Weight (gm) & Abrassion Loss (gm) & Loss \% \\
\hline $1 \mathrm{Kg}$ & 1.5954 & 1.3807 & 0.2147 & 13.46 \\
\hline $2 \mathrm{Kg}$ & 1.3807 & 1.0877 & 0.2930 & 21.22 \\
\hline $3 \mathrm{Kg}$ & 1.0877 & 0.6866 & 0.4011 & 36.88 \\
\hline
\end{tabular}

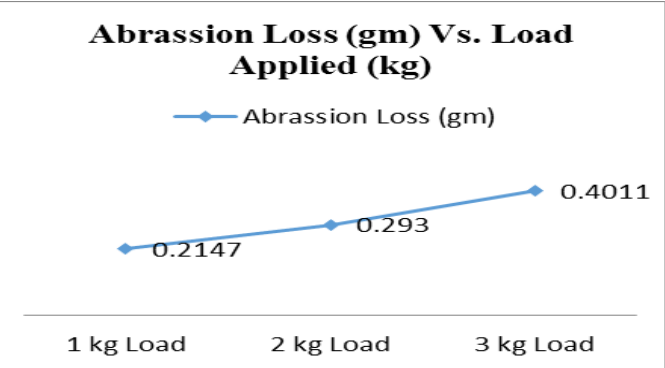

Figure.6. Wear test in $2 \%$ composite as a function of weight loss

Figure.6, shows that the abrasion loss increases with the load applied for the $2 \% \mathrm{TiB}_{2}$ sample. The loss is minimum at the starting when the load applied is $1 \mathrm{~kg}$ and increases thereafter with the load applied.

Aluminium Alloy Reinforced With 6\% $\mathbf{T i B}_{2}$ : Table.7, shows the result of wear load test conducted on 6\% composite.

Table.7. Wear load test values on $6 \%$ composite

\begin{tabular}{|l|l|l|l|l|}
\hline Load Applied & Initial Weight (gm) & Final Weight (gm) & Abrassion Loss (gm) & Loss \% \\
\hline $1 \mathrm{Kg}$ & 1.6118 & 1.4165 & 0.1953 & 12.12 \\
\hline $2 \mathrm{Kg}$ & 1.4165 & 1.1400 & 0.2765 & 19.52 \\
\hline $3 \mathrm{Kg}$ & 1.1400 & 0.7241 & 0.4159 & 36.48 \\
\hline
\end{tabular}

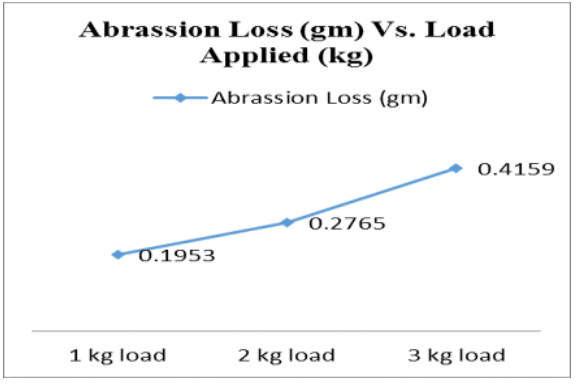

Figure.7. Wear test in $6 \%$ composite as a function of weight loss

Figure.7, shows the abrasion loss increases with the load applied for the $6 \% \mathrm{TiB}_{2}$ sample. The loss is minimum at the starting when the load applied is $1 \mathrm{~kg}$ and increases thereafter with the load applied.

Abrassion Loss Comparision among Aluminium Alloy And 2\%, 6\% Composite:

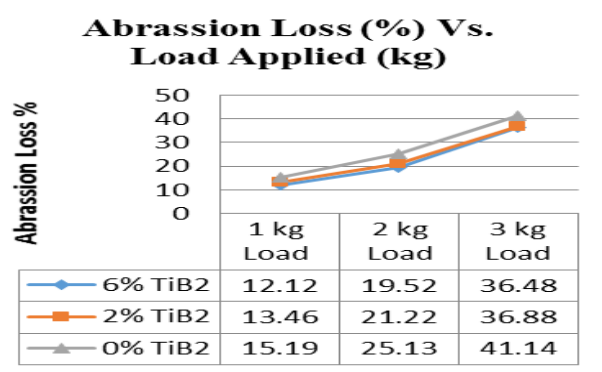

Figure.8. Abrasion loss \% among aluminium alloy and $2 \%, 6 \%$ composite with varying loads

Figure. 8 , shows that abrasion loss is minimum for the $6 \% \mathrm{TiB}_{2}$ sample and is minimum for the aluminium alloy. The $2 \% \mathrm{TiB}_{2}$ sample has an intermediate abrasion loss as should be the case. The Figure also shows that with the increase in the load applied, the abrasion loss also increases. The abrasion loss shows a gradual increase for 
Sun International Journal of Engineering and Basic Sciences

weights up to $2 \mathrm{~kg}$ and increases steeply thereafter for increasing loads. The abrasion loss is maximum in case of the aluminium alloy. The trend in case of the aluminium alloy is different from the other two reinforced samples and shows the steepest rise in abrasion loss when the load is increased from $2 \mathrm{~kg}$ to $3 \mathrm{~kg}$.

Compression Load Test:

Aluminium Alloy Reinforced With 2\% TiB $_{2}$ :

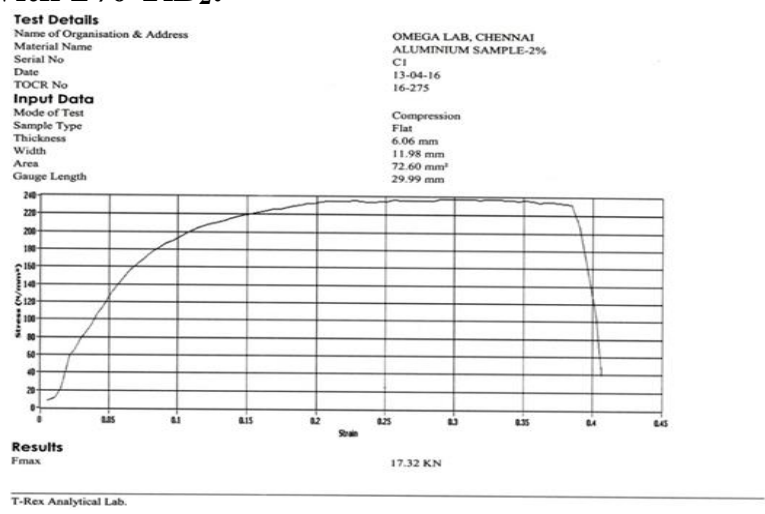

Figure.9. Stress vs. Strain graph for aluminium alloy reinforced with $2 \% \mathrm{TiB}_{2}$

Figure.9, shows the stress versus strain graph for the aluminium alloy reinforced with $2 \%$ titanium diboride. The graph follows almost a straight line in the starting region of the graph which is referred to as the area of uniform deformation. After reaching a peak stress value of $238.56 \mathrm{~N} / \mathrm{mm}^{2}$, the graph is non-uniform which is also referred as the area of non-uniform deformation.

Aluminium Alloy Reinforced With 6\% $\mathrm{TiB}_{2}$ :

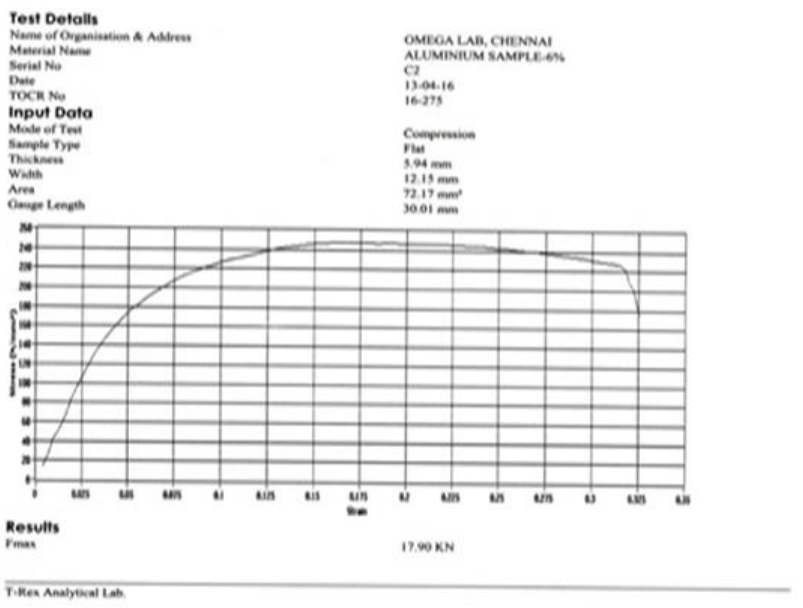

Figure.10. Stress Vs. Strain graph for aluminium alloy reinforced with $6 \% \mathrm{TiB}_{2}$

Figure.10, shows the stress versus strain graph for the aluminium alloy reinforced with $6 \%$ titanium diboride. The graph follows almost a straight line in the starting region of the graph which is referred to as the area of uniform deformation. After reaching a peak stress value of $248.02 \mathrm{~N} / \mathrm{mm}^{2}$, the graph is non-uniform which is also referred as the area of non-uniform deformation.

Compressive Strength Comparison among Aluminium Alloy and 2\%, 6\% Composite:

Table.8. Compressive strength comparison

\begin{tabular}{|l|l|l|l|}
\hline $\mathrm{TiB}_{2}(\%)$ & $0 \%$ & $2 \%$ & $6 \%$ \\
\hline $\begin{array}{l}\text { Compression Strength } \\
(\mathrm{MPa} \text { or N/mm }\end{array}$ & 180.45 & 238.56 & 248.02 \\
\hline
\end{tabular}

Figure.11, shows a comparison of the compressive strength among the aluminium alloy and $2 \%, 6 \% \mathrm{TiB}_{2}$ composite. The comparison shows that the compressive strength of the aluminium alloy reinforced with $6 \%$ titanium diboride is maximum while the compressive strength of the aluminium alloy is the minimum among the three samples. The $2 \% \mathrm{TiB}_{2}$ sample shows an intermediate value of compressive strength among the three samples. The increase in the compressive strength of the alloy when it is reinforced with titanium diboride indicates that the alloy can now withstand greater loads tending to reduction in size. 
Sun International Journal of Engineering and Basic Sciences

Sliding Wear Test:

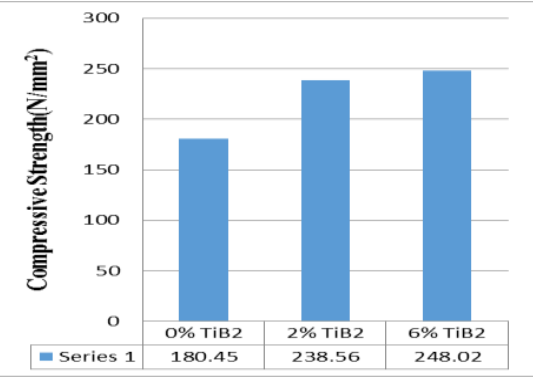

Figure.11. Compressive strength bar chart

Comparison Between Aluminium Alloy and Aluminium Alloy Reinforced With $6 \% \mathrm{TiB}_{2}$ :

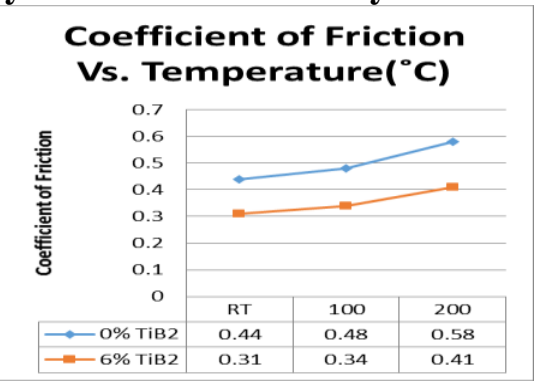

Figure.12. Coefficient of friction as a function of temperature

Comparison between aluminium alloy and aluminium alloy reinforced with $6 \% \mathrm{TiB}_{2}$ : Figure.13, shows that the coefficient of friction for composite is less than that of the alloy. Figure.12, shows that coefficient of friction starts to increase with increase in temperature of the working conditions.

\section{Coefficient of friction Vs.} Wt. \% of TiB2

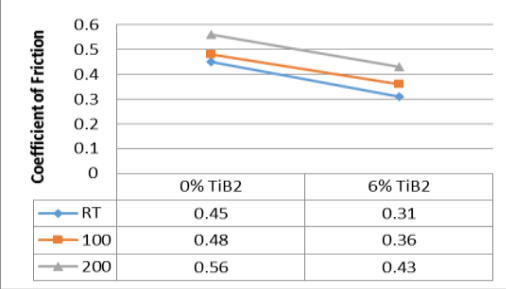

Figure.13. Coefficient of friction as a function of wt. $\%$ of $\mathbf{T i B}_{2}$

Microstructure Analysis: The microstructure of matrix base alloy and the $\mathrm{Al} / \mathrm{TiB}_{2} \mathrm{MMC}_{\mathrm{C}}$ composites is shown in Figure. 4 for load case of $30 \mathrm{~N}$ and speed of $300 \mathrm{rpm}$. The worn surface was characterized by fairly long and extensive ploughing grooves for the aluminium alloy. Short cracks parallel to sliding direction were present at the bottom of the grooves. It is noticed from Figure. 4 that groove width size in the aluminium alloy was bigger when compared to composites.

Aluminium Alloy:

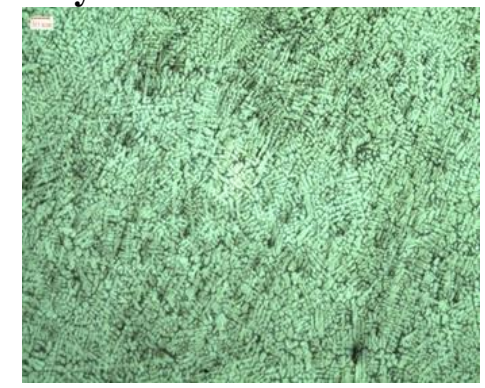

Figure.14. Aluminium alloy at 50X magnification

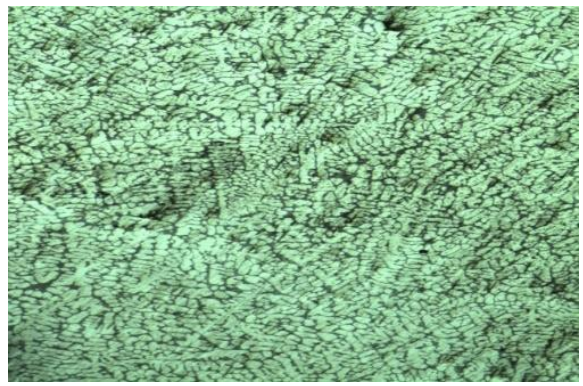

Figure.15. Aluminium alloy at 100X magnification The reflective part of the magnified images indicated in Figure 14 and 15 shows the presence of aluminium matrix. 
Sun International Journal of Engineering and Basic Sciences

Aluminium Alloy Reinforced With 6\% TIB $_{2}$ :

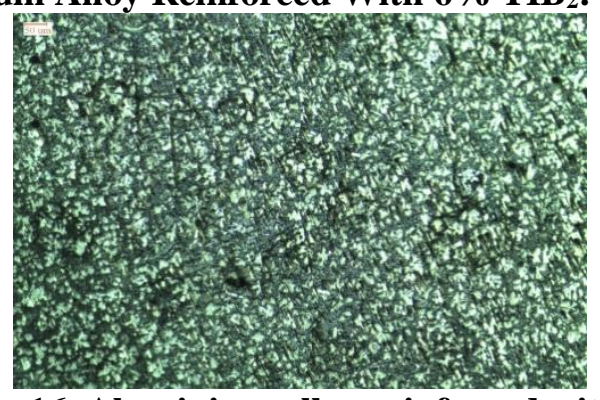

Figure.16. Aluminium alloy reinforced with $6 \%$ $\mathrm{TiB}_{2}$ at $50 \mathrm{X}$ magnification

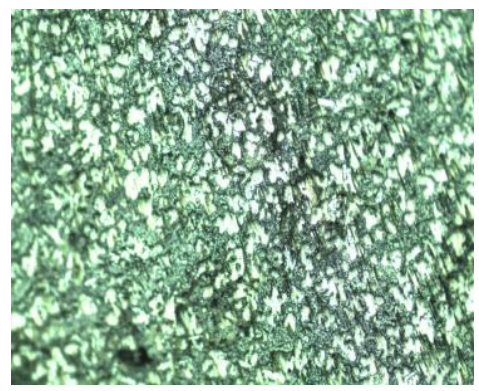

Figure.17. Aluminium alloy reinforced with $6 \%$ $\mathrm{TiB}_{2}$ at $100 \mathrm{X}$ magnification

The reflective part of the magnified images indicated in Figure.16 and 17, shows the presence of aluminium matrix while the darker region surrounding the aluminium matrix shows the presence of $\mathrm{TiB}_{2}$ particles.

Aluminium alloy reinforced with $2 \% \mathrm{TIB}_{2}$ :

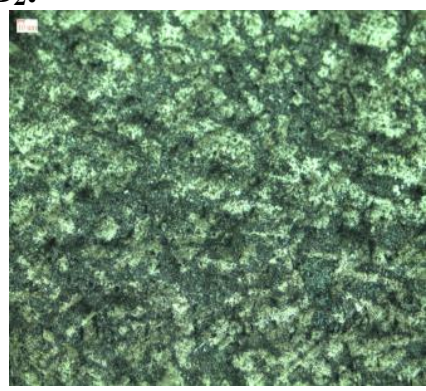

Figure.18. Aluminium alloy reinforced with $2 \% \mathrm{TiB}_{2}$ at $50 \mathrm{X}$ magnification

The reflective part of the magnified images indicated in Figure.18 and 19 shows the presence of aluminium matrix while the darker region surrounding the aluminium matrix shows the presence of $\mathrm{TiB}_{2}$ particles.

The discontinuous $\mathrm{TiB}_{2}$ particles reinforcement phase, being non uniform in size and irregularly shaped, were found to be dispersed randomly through the aluminium alloy matrix. Agglomerations of the $\mathrm{TiB}_{2}$ particles reinforcements of varying sizes and shapes were observed to be present in the $\mathrm{Al}$ alloy matrix. The micro hardness of the base alloy increased with addition of $\mathrm{TiB}_{2}$ particulate.

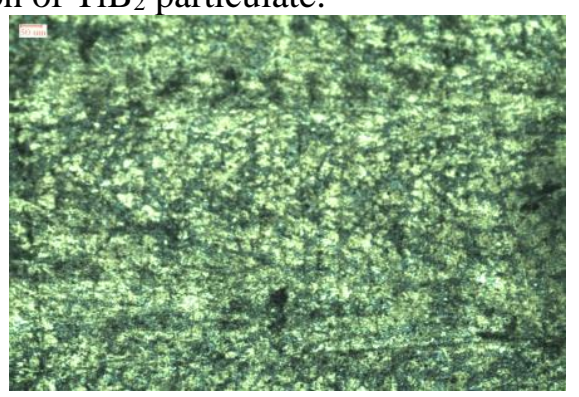

Figure.19. Aluminium alloy reinforced with $2 \% \mathrm{TiB}_{2}$ at $100 \mathrm{X}$ magnification

Scanning electron micrographs of the fractured surface of the base alloy and Al MMC specimens provided evidences for locations where the reinforcement particles had resided in the matrix.

\section{CONCLUSION}

- The characterisation test confirms the presence of titanium diboride particles in the aluminium alloy matrix and hence the operation becomes feasible for industrial applications.

- The results of the microstructural studies revealed the absence of voids and reaction products, indicating good interfacial integrity between the in-situ produced titanium diboride.

- The average grain size of the aluminium titanium diboride composite is less than the aluminium alloy which indicates an increase in the strength of the composite. The decrease in the grain size of the composite may be attributed to the presence of fine titanium diboride particles.

- The micro hardness test shows an increase in the strength of the composite when compared to that of the alloy which may be attributed to the presence of titanium diboride particles in the composite.

- The compression load test shows an increase in the compressive strength of the aluminium titanium diboride when compared to that of the aluminium alloy which may be attributed to grain refinement which makes the dislocation of the particles difficult. This in turn improves the resistance to plastic deformation resulting in increased hardness. 
Sun International Journal of Engineering and Basic Sciences

- The wear load test shows that abrasion loss decreases with the reinforcement of titanium diboride particles in the aluminium alloy which indicates an increase in wear resistance of the alloy when it is reinforced with titanium diboride. Further, an increase in the amount of reinforcement further increases the wear resistance of the alloy.

- The sliding wear test shows that the coefficient of friction decreases when the aluminium alloy is reinforced with titanium diboride particles.

\section{REFERENCES}

Degnan CC, Shipway PH, Wood JV, Elevated temperature sliding wear behaviour of TiC-reinforced steel matrix composites, Wear, 251 (1-12), 2001, 1444-1451.

Deng Jianxin, Friction and wear behaviour of $\mathrm{Al}_{2} \mathrm{O}_{3} / \mathrm{TiB}_{2} / \mathrm{SiC}_{\mathrm{w}}$ ceramic composites at temperatures up to $800^{\circ} \mathrm{C}$, Ceramics International, 27 (2), 2001, 135-141.

Hemalatha K, Venkatachalapathy V.S.K, Alagumurthy N, Processing and synthesis of Metal Metrix A16063 MMC by stir casting process, Int. Journal of Engineering Research and Applications, 3 (6), 2013, 1390-1394

Lim SC, Ashby MF, Overview no. 55 wear-mechanism maps, Acta Metallurgica, 35 (1), 1987, 1-24.

Liu Yao-hui, Du Juna, Yu Si-rong, Wang Wei, High temperature friction and wear behaviour of $\mathrm{Al}_{2} \mathrm{O}_{3}$ and/or carbon short fibre reinforced Al-12Si alloy composites, Wear, 256 (3-4), 2004, 275-285.

Quinn TFJ, Sullivan JL, Rowson DM, Origins and development of oxidational wear at low ambient temperatures, Wear, 94 (2), 1984, 175-191.

Rupa Dasgupta, Aluminium alloy based Metal Matrix Composites: A Potential Material for Wear Resistant Application, International Scholarly Research Network, ISRN Metallurgy, 2012, 14.

Singh J, Alpas AT, Elevated temperature wear of Al6061 and A16061-20\% $\mathrm{Al}_{2} \mathrm{O}_{3}$, Scripta Metallurgica et Materialia, 32 (7), 1995, 1099-1105.

Stott FH, High-temperature sliding wear of metals, Tribology International, 35 (8), 2002, 489-495.

Surappa M.K, Al-MMC Composites, Challenges and Opportunities, Sadhana, 28 (1\&2), 2003, 319-334. 